\title{
TRENDS IN HOSPITALIZATION OF CHILDREN WITH BACTERIAL PNEUMONIA IN POLAND
}

\author{
Małgorzata Gajewska ${ }^{1}$, Katarzyna Lewtak ${ }^{1}$, Jacques Scheres ${ }^{2,3}$, Piotr Albrecht ${ }^{4}$, Paweł Goryński ${ }^{5}$ \\ 'Department of Health Promotion and Postgraduate Education, National Institute of Public Health - National Institute of Hygiene, Warsaw, \\ Poland \\ ${ }^{2}$ Maastricht University Medical Centre, Maastricht, The Netherlands \\ ${ }^{3}$ Department of Organization, Health Economics and Hospital Management, National Institute of Public Health - National Institute of Hygiene, \\ Warsaw, Poland \\ ${ }^{4}$ Department of Paediatric Gastroenterology and Nutrition, Medical University of Warsaw, Poland \\ ${ }^{5}$ Centre for Monitoring and Analyses of Population Health Status and Health Care System, National Institute of Public Health - National Institute \\ of Hygiene, Warsaw, Poland
}

\section{SUMMARY}

Aim: The aim of the study was to evaluate the hospitalization trends in children aged 0-6 suffering from bacterial pneumonia in the years 2007-2011 in Poland.

Methods: The data pertained to the hospitalized patients diagnosed with the diseases registered as J13-J15 according to ICD-10.

Results: In the years 2007-2011, the hospitalization rate increased from 16.3/10,000 to 44.1/10,000 for boys and from 13.8/10,000 to 33.0/10,000 for girls. The most frequently hospitalized children were between 1 and 2 years of age (90.6/10,000 for boys and 58.0/10,000 for girls in 2011). The average length of stay (LOS) of the investigated children fell from 10.1 days in 2007 to 8.2 days in 2011. The longest stays were recorded for the youngest children, under 2 years of age (from almost 11 days in 2007 to around 9 days in 2011).

Conclusion: Bacterial pneumonia is a serious problem of public health and especially babies are at high risk of this disease. Given the effects of vaccinations against Streptococcus pneumoniae conducted all over the world and to a limited extend in Poland as well, further steps towards vaccinating children against pneumococci should be taken in Poland.

Key words: children, epidemiology, hospitalization, pneumonia, vaccination

Address for correspondence: K. Lewtak, Department of Health Promotion and Postgraduate Education, National Institute of Public Health National Institute of Hygiene, 00-791 Warsaw, Chocimska Str. 24, Poland. E-mail: klewtak@pzh.gov.pl

http://dx.doi.org/10.21101/cejph.a4164

\section{INTRODUCTION}

The inflammations of the lower respiratory tract are regarded as the main cause of morbidity and mortality of children (1-3). Community-acquired pneumonia is the leading cause of hospitalization in children's wards both in developed and developing countries $(4,5)$.

There are many aetiologic factors that cause pneumonia, such as Streptococcus pneumoniae, Haemophilus influenzae, Staphylococcus aureus, Legionella pneumophila as well as Gram negative bacilli. Many studies show that $S$. pneumoniae is the most frequent pathogen of invasive bacterial infections of children and it is responsible for the majority of cases of pneumonia in this age group $(4,6)$. A serious course of the disease often requires hospitalization $(7,8)$. As evidenced by research, the most invasive infections concern babies under 2 years of age $(9,10)$. The infections caused by $S$. pneumoniae are regarded as infections with a high mortality. According to the estimates of the World Health Organization (WHO), this bacteria causes $12 \%$ of deaths of children under the age of 5 in the European region (11).

Due to its high health and life risk, according to the recommendations of the British Thoracic Society, Pediatric Infectious
Diseases Society and Infectious Diseases Society of America, bacterial pneumonia of babies under 3 months of age is usually treated in hospital conditions. Also older children are frequently hospitalized, especially when suffering from immunosuppression, tachypnea, dyspnea, fever, dehydration symptoms, vomiting, general severe condition with toxic and septic symptoms as well as neurological symptoms (disorders of consciousness, convulsions). Hospital admission is also recommended in case of lack of health improvement after 3 days of treating pneumonia at home, disease regression or complication, and also for reasons of social nature (12).

The purpose of the present study was to assess the hospitalization trends in children aged 0-6 suffering from pneumonia with bacterial aetiology in the years 2007-2011 in Poland.

\section{MATERIALS AND METHODS}

The data on the hospitalized patients in Poland in the years 2007-2011 were collected from the nation-wide database stored in the National Institute of Public Health - National Institute of Hygiene in Warsaw. This database contains information collected 
within the framework of the Statistical Research of Public Statistics Programme, which covers almost all hospitalized cases (ie. $98 \%$ of hospitals in Poland send monthly data to the database, which accounts for approximately 7 million records annually). The statistical research programme is annually approved by the Prime Minister, and each hospital has a statutory reporting obligation in this regard. Data regarding incidence of bacterial pneumonia are presented according to the International Statistical Classification of Diseases and Related Health Problems 10th Revision (ICD-10, valid since 1997). In hospitals, codes based on diagnosis established by the doctor and recorded in the patient's medical records are given by the hospital statistical unit. The collected data from general hospitals cover the period from 2007-2011.

The study analyzed the data pertaining to children aged $0-6$, qualified on the grounds of date of birth (date of hospital discharge - date of birth). For all the investigated children the major cause of hospitalization was pneumonia. According to the ICD-10, we collected the data on patients hospitalized because of bacterial pneumonia (i.e. S. pneumoniae (J13), H. influenzae (J14) and bacterial pneumonia, not classified elsewhere (J15)). In the further part of the present study, the term of pneumonia is used for this group of diseases.

The analysis took into account age, gender, domicile (city or country), and length of stay (LOS) in hospital. The estimation of frequency of occurrence of pneumonia was calculated on the basis of the hospitalization rate (the number of children hospitalized per year in relation to the analyzed population).

The data were processed statistically with SPSS 12 package. The chi-square test was applied to evaluate the differences between the hospitalization rate for different age groups, gender and domicile. The Cochrane-Armitage test for linear trend was used for verification of the null hypothesis. The significance level for hypothesis testing was set at $\mathrm{p}=0.05$.

\section{RESULTS}

Between 2007 and 2011, the number of hospitalized children due to bacterial pneumonia (J13-J15) varied from 3,822 to 11,466. This constituted $0.5 \%$ in 2007 and $1.2 \%$ in 2011 of all children aged up to 6 years hospitalized during this period.

Boys were significantly $(\mathrm{p}<0.05)$ more often hospitalized than girls and the ratio of hospitalized boys/girls (B/G ratio) gradually increased in the period 2007-2011 (Fig. 1). In the years 2007 and 2008 , the hospitalization rate of children was 16.3 and $16.8 / 10,000$ for boys and 13.8 and 13.5/10,000 for girls. In the subsequent years the incidence of hospitalizations increased significantly. In 2011, the hospitalization rate for boys was 44.1/10,000, while for girls it was 33.0/10,000.

The most frequently hospitalized group were children aged 1-2 (Fig. 2). In 2011, the hospitalization rate for this age group was 90.6/10,000 for boys and 58.0/10,000 for girls. In all analyzed years the statistically significant trend of hospitalization decreasing with age in boys and girls has been observed reaching in 2011 the value of 17.0/10,000 for boys and 15.2/10,000 for girls (both in the age of 6 years). Fig. 3 presents data on children's hospitalization in relation to the degree of urbanization. In all analyzed years children coming from cities were more frequently admitted to hospitals than those from the country $(p<0.05)$. Over the

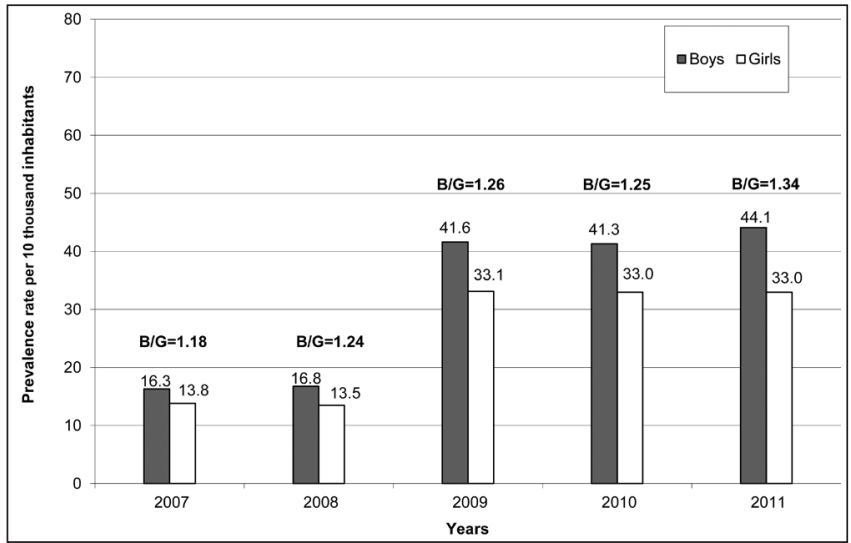

Fig. 1. Hospitalization of children aged 0-6 in Poland due to pneumonia (ICD-10, J13-15 in the years 2007-2011).

$B / G$ - boys/girls ratio; boys vs. girls $p<0.05$

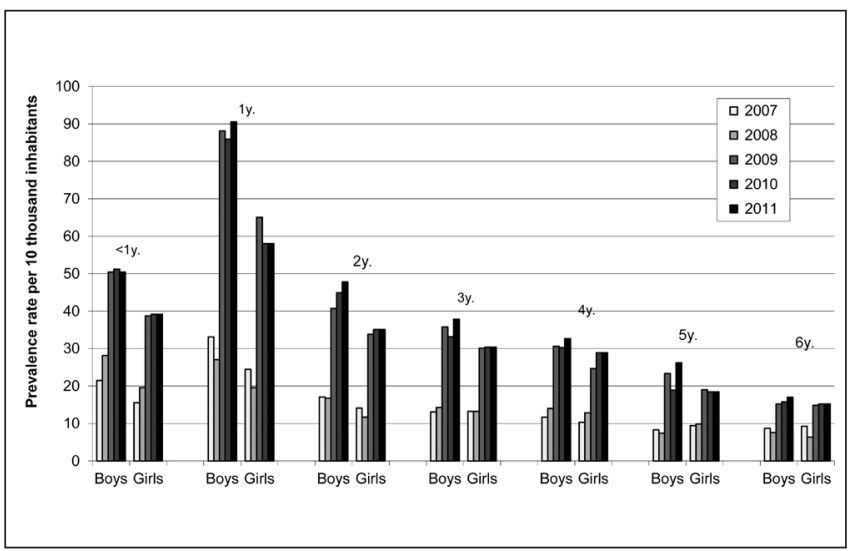

Fig. 2. Hospitalization of children aged 0-6 in Poland due to pneumonia (ICD-10, J13-15) in the years 2007-2011 categorized by gender and age groups.

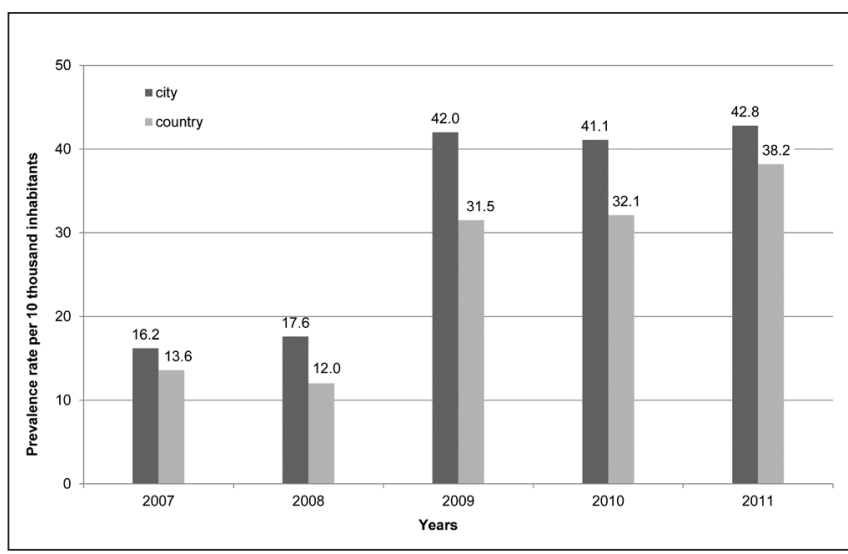

Fig. 3. Hospitalization of children aged 0-6 in Poland due to pneumonia (ICD-10, J13-15) in the years 2007-2011 categorized by place of residence.

city vs. country $\mathrm{p}<0.05$

period of 5 years the hospitalization rate rose more than 2.5 times for both patients from cities and those from the country (from 16.2/10,000 for children from cities and 13.6/10,000 for children from the country, in 2007 , to $42.8 / 10,000$ and $38.2 / 10,000$, respectively, in 2011). 
In the analyzed period the average LOS in hospital fell down by almost two days (from 10.1 days in 2007 to 8.2 days in 2011 (Fig. 4). The longest stays were recorded for the youngest children, under 2 years of age (from almost 11 days in 2007 to around 9 days in 2011). LOS of children from the older age groups, on the other hand, was much shorter (9.7 days for 6-year-olds in 2007 and 7.4 days for 4-year-olds in 2011).

\section{DISCUSSION}

One of the most significant challenges for public health all over the world is that antibiotic-resistant microorganisms, including pneumococci, circulate on a wider scale than before, and especially that these resistant microorganisms display increasingly high drug-resistance mechanisms $(5,7,10)$.

Also in Poland, a significant increase in the hospitalization rate of babies caused by bacterial pneumonia was observed during the period 2009-2011 compared to the previous years (in 2011 the hospitalization rate for boys was 44.1/10,000, while for girls it was 33.0/10,000). A more than 2,5-fold jump in hospitalization rate occurred between these periods.

Even before 2006 an annual growth of the hospitalization rate of children due to pneumonia had been observed also in,

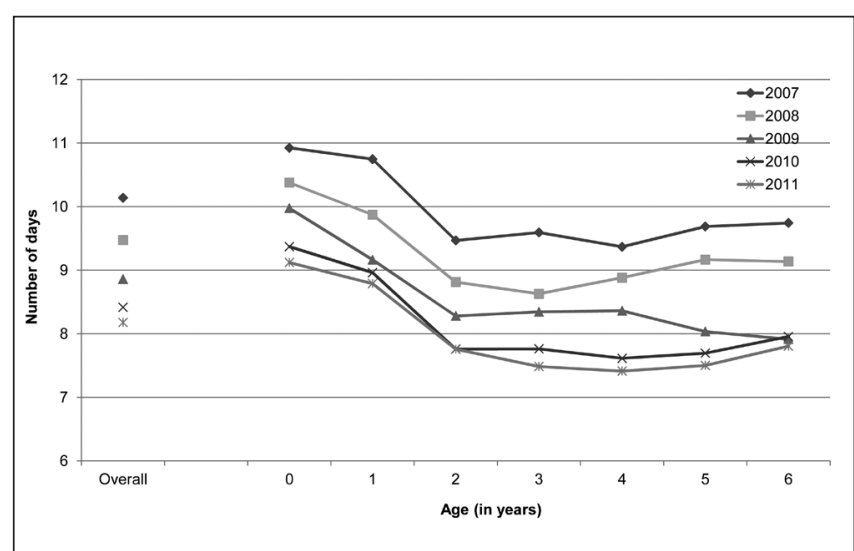

Fig. 4. Average length of stay (LOS) in hospital (in days) of children aged 0-6 in Poland due to pneumonia (ICD-10, J13-15) in the years 2007-2011.

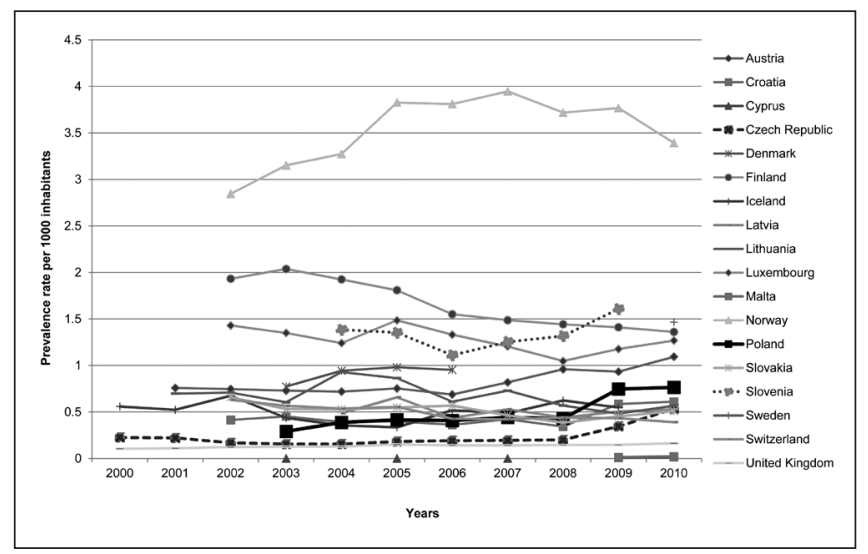

Fig. 5. Hospitalization of children aged 0-9 in Poland and some other European countries due to pneumonia (ICD-10, J13-15) in the years 2000-2010. among others, England and Scotland $(14,15)$. As suggested by researchers from the UK, one of the possible explanations for the increase in the hospitalization rate of children caused by bacterial pneumonia is the rise of the number of infections caused by drug-resistant pneumococcal serotypes.

According to the EARS-Net interactive database of the European Centre for Disease Prevention and Control (ECDC) website, Poland shows an increase in antimicrobial resistance trends for most of the isolates. For example, with regard to $S$. pneumoniae data related to proportion of invasive isolates non-susceptible to penicillin (PNSP) indicated an increase from a relatively high level (10-25\%) in 2008 to a high level (25-50\%) in 2009. In subsequent years (2010-2011) PNSP decreased again to below $25 \%$ (16). However, when assessing these data the fact that Poland started to consistently report data on antimicrobial resistance only in 2009 should be taken into account. Therefore, it is possible to study real trends of resistance only from 2009 onwards.

Data on hospitalization of children due to bacterial pneumonia in selected European countries could be found, among others, in The European Hospital Morbidity database published on the website of the World Health Organization Regional Office for Europe (17). In countries such as Slovenia or the Czech Republic, like in Poland, there has been recently an increase in the hospitalization rate of children up to 9 years of age caused by pneumonia (Fig. 5). This might have been influenced by the uptake of Pneumococcal Conjugated Vaccines (PCV7), but also by changes in the healthcare systems in these countries. For example in Poland the distribution of paediatricians in the healthcare system indicates a more than two-fold more frequent employment of paediatricians in hospitals than in primary healthcare (outpatient care).

In the recent years, a significant increase in the frequency of use of medical care in emergency departments has been observed.

The changes may also involve coding practices. As it is practiced in many other countries, in mid-2008 Poland implemented a national system of DRG (diagnosis-related group), which groups the corresponding disease entities for the purpose of accounting hospital services.

All the mentioned factors could have an impact on the observed increase in the number of hospitalizations due to bacterial pneumonia among children in 2009 and in the subsequent years. Additional studies are needed to determine the underlying epidemiological or socioeconomic factors associated with these changes.

In order to decrease the risk of contracting a disease and getting complications caused by pneumococcal infections physicians advise using Pneumococcal Conjugated Vaccines (formerly, PCV7, now, PCV10 and PCV13). Pneumococcal vaccines have been included in the National Immunization Programmes in $44 \%$ of the member states of WHO (18). In the European region this strategy has been implemented by $49 \%$ of states. One example can be the UK, where the hospitalization rate of children aged $0-15$ rose by $31 \%$ in the years $1997-2005$. However, after the introduction of vaccines (PCV7), it fell by $19 \%$ (14). On the other hand, as demonstrated by research conducted in the USA, the inclusion of PCV7 vaccine into the CDC's vaccines for infants and children resulted in the fall of the hospitalization rate due to all-cause pneumonia by $39 \%$ over the period of 8 years. For pneumococcal pneumonia hospitalization this rate fell by $65 \%$ (19).

In Poland, the vaccines against invasive infections caused by $S$. pneumoniae are only "recommended", which means that 
they are not refunded by the Ministry of Health. Vaccinations are obligatory and thus refunded for children belonging to high-risk groups, e.g., those with a defect of the central nervous system, infected with HIV, after bone marrow transplantation, or suffering from some chronic disease. They are also refunded for children born before the 37 th week of pregnancy or those who weighed less than $2.5 \mathrm{~kg}$ after birth (20).

Unfortunately, there is no recent data on the use of PCV7 and there is no vaccination history of children hospitalized due to bacterial pneumonia in Poland. The latest data, presented by De Carvalho Gomez et al. in 2009 (21), concerned the years 2006 to 2007. They indicated low numbers of sold PCV7 doses per 100 live births in Poland in these years as compared to many other EU countries.

A notable exception in Poland is the pneumococcal vaccine programme encompassing children in Kielce (22). The vaccines are not financed by the state but by the municipality. Children aged 3-14 months living in this area are given three doses of the vaccine. With this schedule the incidence of pneumonia among babies under 2 years of age fell down by over $80 \%$ in the years 2005-2010. Patrzałek et al. also noted a decrease in the incidence of pneumonia in older age groups, though to a lesser degree (22).

Children under 5 years of age are particularly prone to pneumonia, however, the greatest number of complications which are dangerous for health and life are found in the group of babies under 2 years of age (12-14). This age group has boasted the highest number of hospitalizations for many years now $(14,19)$.

At the same time there is no evidence for a significant decrease of the number of hospitalizations caused by pneumonia among older children (2-4 years of age) (23). When conducted on a mass scale, pneumococcal vaccinations had a significant effect on the risk of incidence and mortality from other serious invasive pneumococcal infections, such as sepsis, meningitis, or less serious non-invasive infections, such as otitis media $(24,25)$.

Some studies indicated that the hospitalization rate of children for pneumonia decreases with age, and a similar trend is observed in studies conducted in other areas $(1,5,14)$. Babies from the youngest age group are at the highest risk of contracting invasive and non-invasive pneumococcal disease, due to immaturity of the immune system and favourable anatomical conditions. These factors seem to be responsible for a high hospitalization rate in this age group $(4,5,14)$.

Boys show a higher hospitalization rate than girls, and this trend is observed in all age groups, also in studies conducted by some other authors $(12,14)$.

The present study showed statistically significant differences in the hospitalization rate of children living in cities and in the country. Polish city residents are more frequently treated in hospitals than patients living in the country, though this unfavourable difference is gradually decreasing (26). According to the research of Blain et al., the risk of hospitalization of children caused by pneumonia is connected with material deprivation, Child Wellbeing Index (CWI) health domain score, the number of children requiring local authority support, and the distance to the hospital (27). Also high regional variation in relation to the hospitalization rate is reported in some other studies $(1,27)$.

Pneumonia involves high costs incurred by the necessity of out-patients clinic treatment or hospital treatment $(3,24,28-30)$. In a study of the costs of hospitalization of 99 Italian children it was estimated that the average cost of hospital treatment of pneumonia of one child is 1,435-2,553 EUR (28). Studies in Germany within the PRIDE project indicate that the average costs of the treatment of a baby with pneumonia aged $0-36$ months is 85 EUR when treatment is provided in the out-patient clinics. On the other hand, hospitalization raises the treatment costs with a factor of 25 or more to 2,300 EUR (29).

Unfortunately, in Poland there are no specific analyses of the costs of hospitalization associated with the treatment of bacterial pneumonia in children available. There have only been attempts to estimate the financial effect of PCV7 vaccination in Kielce (30). The analysis showed that in 2006, after the introduction of mass vaccination of children aged 3-14 months living in Kielce, the number of hospitalizations due to pneumonia among children under 2 years of age has decreased during the following years (from 83 in 2005 to 26 in 2009). It has been calculated that as result the savings amounted to approximately PLN 174,000 per year (about 41,000 Euro per year).

In the years 2007-2011, the median LOS of children with pneumonia in Poland fell down by 2 days to 8.2 days. This is in line with the generally observed tendency to reduce the patients' length of stay in hospital in order to reduce the costs of treatment.

According to estimates conducted in the USA, as regards the total number of days of hospitalization, almost $47 \%$ of cases were caused by bacterial pneumonia and asthma. The cost of hospitalization in relation to these two diseases amounted to over $48 \%$ of all expenses connected with the hospitalization of children (31).

\section{CONCLUSION}

Bacterial pneumonia constitutes a serious problem of public health all over the world due to high risk of health hazards in patients and costs incurred by the necessity of providing both out-patients' clinic treatment and hospital treatment. Children, especially the youngest ones, are prone to these infections to the greatest extent and they demand hospital treatment.

In the years 2009-2011, the hospitalization rate of children aged $0-6$ in Poland rose significantly in all age groups, but especially for babies under 2 years of age.

The implementation of protective vaccinations is nowadays regarded as the most fundamental and effective way of (primary) preventing infections, which allows to avoid contracting pneumonia caused by pathogens included in the vaccine as well as secondary bacterial superinfections. Thus, given the results of vaccination programmes against $S$. pneumoniae of children conducted all over the world and to a limited extent in Poland as well, further action towards increasing the number of vaccinations against pneumococcal infections among children in Poland should be seriously considered.

\section{Conflict of Interests}

None declared 


\section{REFERENCES}

1. Berezin EN, de Moraes JC, Hong T, Todd M, Seljan MP. Pneumonia hospitalization in Brazil from 2003 to 2007. Int J Infect Dis. 2012;16(8):e583e90. doi: 10.1016/j.ijid.2012.02.018.

2. Gajewska M, Goryński P, Seroka W. Hospitalization of children and adolescents in Poland between 2004-2008. Probl Hig Epidemiol. 2013;94(1):71-8.

3. Jetsrisuparb A, Teeratakulpisarn J, Weraarchakul W, Thepsuthammarat K, Sutra S. Health situation analysis of Thai children aged 1-5 years in 2010: implications for health education and health service reform. J Med Assoc Thai. 2012 Jul;95 Suppl 7:S30-42.

4. Farha T, Thomson AH. The burden of pneumonia in children in the developed world. Paediatr Resp Rev. 2005;6(2):76-82.

5. Naheed A, Saha SK, Breiman RF, Khatun F, Brooks WA, Arifeen SE, et al. Multihospital surveillance of pneumonia burden among children aged $<5$ years hospitalized for pneumonia in Bangladesh. Clin Infect Dis. 2009; 48 Suppl 2:S82-9.

6. Michelow IC, Olsen K, Lozano J, Rollins NK, Duffy LB, Ziegler T, et al. Epidemiology and clinical characteristics of community-acquired pneumonia in hospitalized children. Pediatrics.2004;113(4):701-7.

7. Senstad AC, Surén P, Brauteset L, Eriksson JR, Høiby EA, Wathne KO. Community-acquired pneumonia (CAP) in children in Oslo, Norway. Acta Paediatr. 2009;98(2):332-6.

8. Stuckey-Schrock K, Hayes BL, George CM. Community-acquired pneumonia in children. Am Fam Physician. 2012;86(7):661-7.

9. Advisory Committee on Immunization Practices. Preventing pneumococcal disease among infants and young children: recommendations of the Advisory Committee on Immunization Practices (ACIP). MMWR Recomm Rep. 2000;49(RR-9):1-35.

10. Walker CLF, Rudan I, Liu L, Nair H, Theodoratou E, Bhutta ZA, et al. Global burden of childhood pneumonia and diarrhea. Lancet. 2013;381(9875):1405-16.

11. WHO Regional Office for Europe [Internet]. Copenhagen: WHO Regional Office for Europe; c2016 [cited 2016 Aug 3]. WHO and UNICEF launch new plan to cut deaths from diarrhea and pneumonia. Available from: http://www.euro.who.int/en/what-we-do/health-topics/diseaseprevention/vaccines-and-immunization/news/news/2013/04/who-andunicef-launch-new-plan-to-cut-deaths-from-diarrhoea-and-pneumonia.

12. Harris M, Clark J, Coote N, Fletcher P, Harnden A, McKean M. et al British Thoracic Society guidelines for the management of community acquired pneumonia in children: update 2011. Thorax. 2011;66 Suppl 2:iil-23.

13. Wu PS, Huang LM, Chang IS, Lu CY, Shao PL, Tsai FY, et al. The epidemiology of hospitalized children with pneumococcal/lobar pneumonia and empyema from 1997 to 2004 in Taiwan. Eur J Pediatr. 2010;169(7):861-6.

14. Koshy E, Murray J, Bottle A, Sharland M, Saxena S. Impact of the seven-valent pneumococcal conjugate vaccination (PCV7) programme on childhood hospital admissions for bacterial pneumonia and empyema in England: national time-trends study, 1997-2008. Thorax. 2010;65(9):7704.

15. Roxburgh CS, Youngson GG, Townend JA, Turner SW. Trends in pneumonia and empyema in Scottish children in the past 25 years. Arch Dis Child. 2008;93(4):316-8.

16. European Centre for Disease Prevention and Control. Antimicrobial resistance surveillance in Europe 2011. Annual Report of the European Antimicrobial Resistance Surveillance Network (EARS-Net). Stockholm: ECDC; 2012
17. European hospital morbidity database (HMDB) [Internet]. Copenhagen: WHO Regional Office for Europe; c2016 [cited 2016 Aug 3]. Available from: http://www.euro.who.int/en/what-we-do/data-and-evidence/databases/european-hospital-morbidity-database-hmdb2.

18. Centers for Disease Control and Prevention (CDC). Progress in introduction of pneumococcal conjugate vaccine - worldwide, 2000-2012. MMWR Morb Mortal Wkly Rep. 2013;62(16):308-11.

19. Grijalva CG, Nuorti JP, Arbogast PG, Martin SW, Edwards KM, Griffin MR. Decline in pneumonia admissions after routine childhood immunisation with pneumococcal conjugate vaccine in the USA: a time-series analysis. Lancet. 2007;369(9568):1179-86.

20. The Chief Sanitary Inspector Message on Immunization Program for 2013. Dziennik Urzedowy Ministra Zdrowia [Internet]. 2012 [cited 2015 Jul 21];(78):1-22. Available from: http://dziennikmz.mz.gov.pl/ DUM MZ/2012/78/akt.pdf. (In Polish.)

21. De Carvalho Gomes H, Muscat M, Monnet DL, Giesecke J, Lopalco PL. Use of seven-valent pneumococcal conjugate vaccine (PCV7) in Europe, 2001-2007. Euro Surveill. 2009;14(12):pii=19159.

22. Patrzałek M, Gorynski P, Albrecht P. Indirect population impact of universal PCV7 vaccination of children in a $2+1$ schedule on the incidence of pneumonia morbidity in Kielce, Poland. Eur J Clin Microbiol Infect Dis. 2012;31(11):3023-8.

23. Center for Diseases Control and Prevention (CDC). Pneumonia hospitalizations among young children before and after introduction of pneumococcal conjugate vaccine - United States, 1997-2006. MMWR Morb Mortal Wkly Rep. 2009;58(1):1-4.

24. Gentile A, Bardach A, Ciapponi A, Garcia-Marti S, Aruj P, Glujovsky D, et al. Epidemiology of community-acquired pneumonia in children of Latin America and the Caribbean: a systematic review and meta-analysis. Int J Infect Dis. 2012;16(1):e5-15.

25. O'Brien KL, Dagan R. The potential indirect effect of conjugate pneumococcal vaccines. Vaccine. 2003;21(17-18):1815-25.

26. Wojtyniak B, Goryński P, Moskalewicz B, editors. Health state of the Polish population and its determinants. Warsaw: NIPH-NIH; 2012. (In Polish.)

27. Blain AP, Thomas MF, Shirley MD, Simmister C, Elemraid MA, Gorton $\mathrm{R}$, et al. Spatial variation in the risk of hospitalization with childhood pneumonia and empyema in the North of England. Epidemiol Infect. 2014;142(2):388-98.

28. Di Ciommo V, Russo P, Attanasio E, Di Liso G, Graziani C, Caprino L. Clinical and economic outcomes of pneumonia in children: a longitudinal observational study in an Italian paediatric hospital. J Eval Clin Pract. 2002;8(3):341-8.

29. Ehlken B, Ihorst G, Lippert B, Rohwedder A, Petersen G, Schumacher $\mathrm{M}$, et al. Economic impact of community-acquired and nosocomial lower respiratory tract infections in young children in Germany. Eur J Pediatr. 2005;164(10):607-15.

30. Patrzałek M, Albrecht P, Sobczyński M. Indirect, population effect of mass pneumococcal vaccinations (PVC7) on all-cause pneumonia incidence in Kielce, Poland. Przegl Epidemiol. 2011;65(1):51-6. (In Polish.)

31. Lu S, Kuo DZ. Hospital charges of potentially preventable pediatric hospitalizations. Acad Pediatr. 2012;12(5):436-44.

Received November 5, 2014 Accepted in revised form February 26, 2016 